\title{
Microzonation of seismic risk in a low-rise Latin American city based on the macroseismic evaluation of the vulnerability of residential buildings: Colima city, México
}

\author{
V. M. Zobin ${ }^{1}$, A. A. Cruz-Bravo ${ }^{2}$, and F. Ventura-Ramírez ${ }^{2}$ \\ ${ }^{1}$ Observatorio Vulcanológico, Universidad de Colima, Colima, México \\ ${ }^{2}$ Facultad de Ingeniería Civil, Universidad de Colima, Coquimatlán, México \\ Received: 27 October 2009 - Revised: 2 June 2010 - Accepted: 7 June 2010 - Published: 25 June 2010
}

\begin{abstract}
A macroseismic methodology of seismic risk microzonation in a low-rise city based on the vulnerability of residential buildings is proposed and applied to Colima city, Mexico. The seismic risk microzonation for Colima consists of two elements: the mapping of residential blocks according to their vulnerability level and the calculation of an expert-opinion based damage probability matrix (DPM) for a given level of earthquake intensity and a given type of residential block. A specified exposure time to the seismic risk for this zonation is equal to the interval between two destructive earthquakes. The damage probability matrices were calculated for three types of urban buildings and five types of residential blocks in Colima. It was shown that only $9 \%$ of 1409 residential blocks are able to resist to the Modify Mercalli (MM) intensity VII and VIII earthquakes without significant damage. The proposed DPM-2007 is in good accordance with the experimental damage curves based on the macroseismic evaluation of 3332 residential buildings in Colima that was carried out after the 21 January 2003 intensity MM VII earthquake. This methodology and the calculated PDM-2007 curves may be applied also to seismic risk microzonation for many low-rise cities in Latin America, Asia, and Africa.
\end{abstract}

\section{Introduction}

Seismic risk is the probability that social or economic consequences of earthquakes will equal or exceed specified values in an area during a specified exposure time (EERI, 1984). According to this definition, an estimation of the probabi-

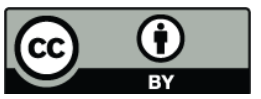

Correspondence to: V. M. Zobin (vzobin@ucol.mx) lity of certain damage to buildings for different areas of a city gives us a microzonation of seismic risk in this city for the period between two destructive earthquakes. Low-rise cities, with one- or two-story urban buildings, and with a population up to 200000-500 000 people are characteristic for many Latin American states. In many cases, they are situated in the regions of high seismic risk. The problem of their seismic risk microzonation is the actual. At the same time, the high cost of multi-disciplinary seismic microzonation work means that it cannot be carried out in the majority of them. We propose a macroseismic methodology of seismic risk microzonation based on the vulnerability of urban buildings. This methodology was firstly proposed and applied in 1999 to predict the probable damage to the houses in a zone of study representing about $20 \%$ of the total territory of Colima city, México (Zobin and Ventura-Ramírez, 1999). The $2003 M_{\mathrm{w}} 7.5$ earthquake (Zobin and PizanoSilva, 2007), occurring at a distance of about $70 \mathrm{~km}$ from the city, had tested the prediction. A good coincidence was observed between the proposed damage probability matrix and the observed damage curves (Zobin et al., 2006). This paper presents the development of the 1999 methodology and its application to the seismic risk microzonation of the total territory of Colima city.

\section{Seismo-tectonic position of Colima city}

Colima city (hereafter Colima), the capital of Colima state, is situated within the Pacific coastal zone of Mexico at a distance of about $60 \mathrm{~km}$ from the coast line (Fig. 1). It is within a region $\mathrm{D}$ of the highest seismic risk, according to the map of seismic zonation of México (Manual, 1993). The high seismic risk results from the convergence between the oceanic Rivera and Cocos plates and the continental North American

Published by Copernicus Publications on behalf of the European Geosciences Union. 


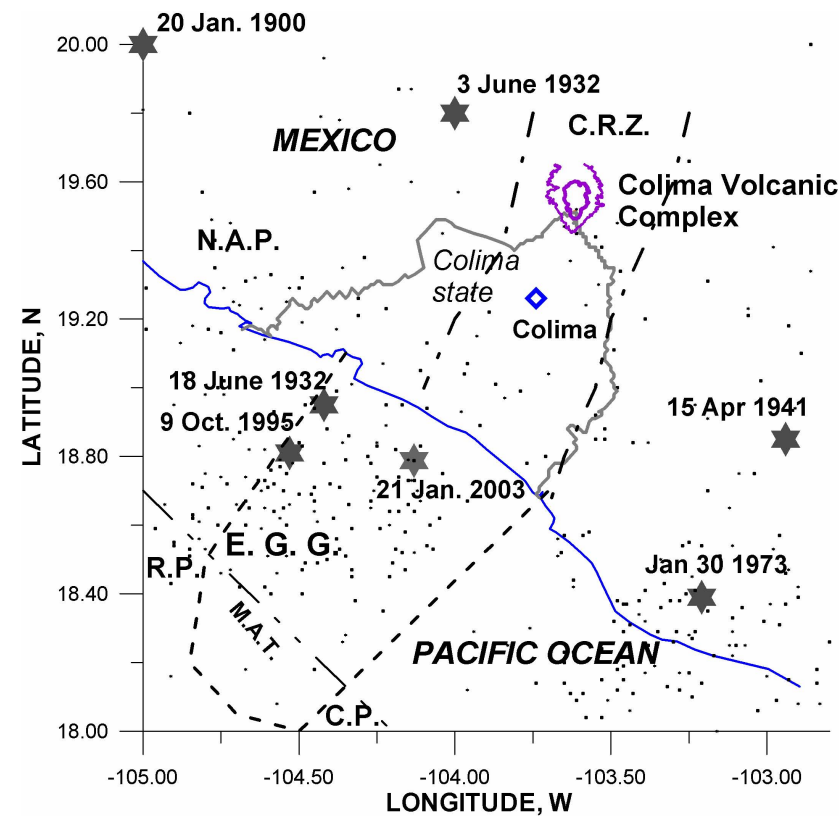

Fig. 1. Seismo-tectonic environment of Colima city. Lithospheric plates are shown (N.A.P., North American Plate; R.P., Rivera Plate; C.P., Cocos Plate), the Middle American Trench (M.A.T., longdashed line), the limits of the El Gordo Graben (E.G.G., shortdashed line) and the limits of the Colima Rift Zone (C.R.Z., dasheddotted line). The stars with date show the epicenters and the date of the $M_{\mathrm{W}} \geq 7.3$ earthquakes that occurred near Colima city during the 20th and 21st centuries. The points show the epicenters of the $M \geq 3.5$ earthquakes occurring during last 10 years. The border of Colima state is shown by a grey line. The position of Colima city is shown by a diamond. The epicenters of the 1932, 1941, and 1973 earthquakes are shown according to Pacheco and Sykes (1992), the 1995 earthquake according to Zobin and VenturaRamírez (1998) and the 2003 earthquake according to Zobin and Pizano-Silva (2007).

plates along the Middle American trench. The earthquakes occurring within the Mexican subduction zone have reached magnitudes up to 8.5 , and have strongly damaged the Colima houses in 1900, 1932, 1941, and 1973. Another important factor of danger is a regional across-trench rift system consisting of the continental Colima rift, within which Colima is situated, and its submarine continuation El Gordo graben (E.G.G.). The E.G.G. is supposed to be the border between the Cocos and Rivera oceanic plates (Bandy et al., 1995). The last destructive $M_{\mathrm{w}} 7.5$ earthquake occurred on $21 \mathrm{Ja}-$ nuary 2003 within this structure.

\section{Soil properties in Colima}

Colima has been built upon a thick (about $800 \mathrm{~m}$ ) sequence of volcanic deposits, consisting of a mixture of avalanches and lahar deposits, and reworked volcanic sediments aged 1800 to 2500 years. These deposits were produced by the ac- tivity of andesitic strato-volcanoes forming the Colima Volcanic Complex located $32 \mathrm{~km}$ to the north of Colima (Fig. 1). The deposits of volcanic debris avalanches consist of andesite rubbles with clasts mainly between 5 and $20 \mathrm{~cm}$ diameter, but with some boulders as large as $1 \mathrm{~m}$. These deposits have great thickness and cover about $80 \%$ of the total territory of the city. The volcanic deposits overlay a late Cretaceous limestone basement outcropping east and west of the city (Chávez-García et al., 2007).

A study of dominant period and maximum amplification by the horizontal-to-vertical spectral ratios (HVSR) and array techniques within the city territory (Chávez-García et al., 2007) showed that there is little variation of the seismic amplification level. Chávez-García et al. (2007) also demonstrated that the isoperiod map was not correlated with surface geology. These results indicated that there are no significant site effects within the city territory, since the ground properties at the sites were sufficiently homogeneous. Variation in seismic risk does not depend upon the differences in soil properties and the seismic microzonation has to be based on another factors. The first of them is the vulnerability of urban buildings.

\section{Vulnerability of urban buildings in Colima}

Vulnerability here refers to the degree of damage that can be suffered by man-made constructions, and it depends on the design, the quality of materials, and the building techniques employed (Kuroiwa, 2004). To study the vulnerability of Colima residential buildings, we introduce a classification of the buildings according to their level of vulnerability and a classification of the residential blocks that represent the main unit of the urban infrastructure.

\subsection{The types of buildings}

The dominant construction types in West México are oneor two-story masonry buildings. They can be divided into three groups according to their design and quality (Zobin and Ventura-Ramírez, 1998):

Type A (Fig. 2a): good quality, low vulnerability. The buildings are designed with some lateral resistance to ground shaking. They are made out of solid masonry units, confined with reinforced concrete (R.C.) bond-beams and columns at a distance of $3 \mathrm{~m}$ and in the corners of the construction. They have floor slabs and some R.C. frames.

Type B (Fig. 2b): intermediate quality, intermediate vulnerability. The buildings are not designed to resist ground shaking. They are made with solid masonry units, confined only in the corners of the construction. There are floor slabs without bond-beams and simple lintels.

Type $C$ (Fig. 2c): poor quality, high vulnerability. Old buildings made out of adobe or cinder block units. They have not any project. They include no resistant elements. Heavy roofs are constructed with free supported wooden beams. 

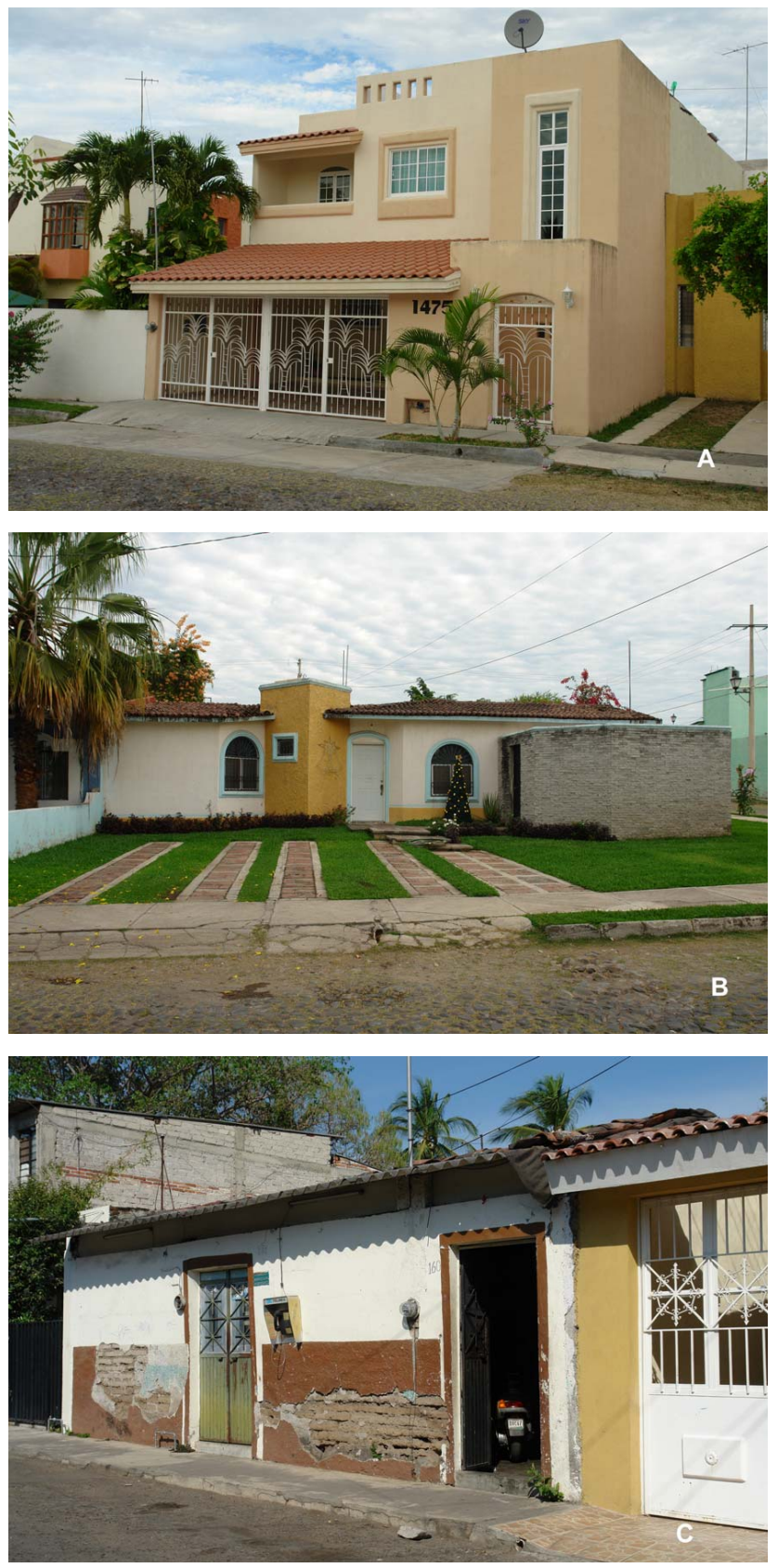

Fig. 2. Examples of three types of buildings: type A (A), type B (B), and type C (C).

Historically, Colima comprised of C-type adobe houses. These buildings were systematically destroyed by the large earthquakes in 1900, 1932, 1941, 1973, and 2003. The construction of masonry buildings of types A and B, mainly beginning after the 1973 earthquake, increased the resistance of Colima to seismic damage. The 2003 earthquake showed, that while the central part of the city was significantly damaged (more than 1000 houses were destroyed or demolished), the masonry buildings constructed after 1990 demonstrated
Table 1. The seven-grade scale of damages (based on Whitman, 1988).

\begin{tabular}{|c|c|c|c|}
\hline DI & $\begin{array}{l}\text { Damage } \\
\text { state }\end{array}$ & $\begin{array}{c}\text { Central } \\
\text { damage } \\
\text { factor } \\
(\%)\end{array}$ & Comments \\
\hline 1 & None & 0 & No fractures in plaster \\
\hline 2 & Slight & 0.5 & $\begin{array}{l}\text { Small, not numerous fractures } \\
\text { in plaster }\end{array}$ \\
\hline 3 & Light & 5 & Diagonal fractures in plaster \\
\hline 4 & Moderate & 20 & $\begin{array}{l}\text { Narrow closed diagonal } \\
\text { cracks in walls }\end{array}$ \\
\hline 5 & Heavy & 45 & $\begin{array}{l}\text { Open diagonal cracks and } \\
\text { spalls in walls }\end{array}$ \\
\hline 6 & Major & 80 & $\begin{array}{l}\text { Partly destroyed construction, } \\
\text { with the intention to demolish }\end{array}$ \\
\hline 7 & Destroyed & 100 & $\begin{array}{l}\text { Total destruction of } \\
\text { the majority of the building }\end{array}$ \\
\hline
\end{tabular}

Note. DI is damage index.

better resistance to the earthquake (Zobin et al., 2006). This was when the first building construction code for seismic design in Colima was introduced by the municipal authorities (Reglamento, 1990). The 7-grade damage scale (Whitman, 1988; Table 1) was applied in order to analyse the damage due to the 2003 earthquake. The first 3 grades of this scale describe insignificant damage to buildings and the grades from 5 to 7 indicate significant damage or destruction of buildings (damage ratio between 60 and 100\%).

Figure 3 shows three zones of the characteristic Colima infrastructure (Fig. 3a) and the distribution of the 2003 earthquake damage to 3332 buildings situated within these three zones (Fig. 3b) according to (Zobin et al., 2006). These three zones were selected by Zobin and Ventura-Ramírez (1999) and they differ in age and quality of buildings. The urban development went from the historical center of the city filled with the old adobe buildings (zone I, subzones I-9, I-111, I-12) through the intermediate age zone II (subzones II-5, II7, II-8, II-10) to the modern zone III (subzones III-1, III-2, III-3, III-4, III-6).

In zone III (Fig. 3b), where the modern A-type buildings were the majority, $80 \%$ of houses suffered insignificant damage (damage grades 1-3) and only $0.5 \%$ was demolished (damage grade 6). The buildings of zone II, with the majority of B-type houses, were characterized by demolition of $8 \%$ of the constructions (damage grade 6) and $50 \%$ of them had insignificant damage (damage grades 1-3). In zone I, where many old C-type adobe buildings were still found together with modern A- and B-type houses, about $20 \%$ of all buildings were destroyed or demolished (damage grades 6-7) but 

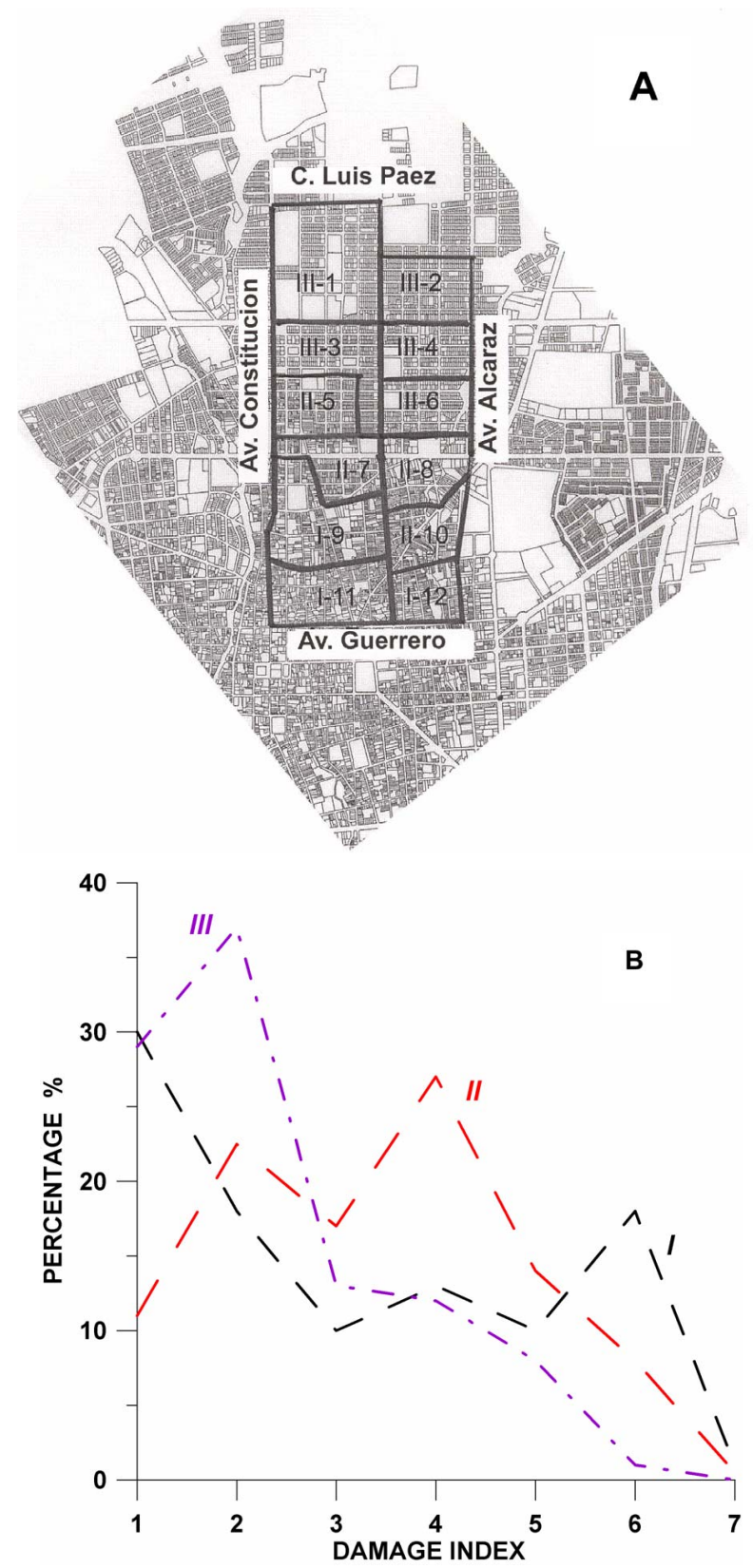

Fig. 3. Three zones (a) of the characteristic Colima infrastructure (I, II, III) where the macroseismic study after the 2003 earthquake (Zobin et al., 2006) was carried out and the distribution of the 2003 earthquake damage to 3332 buildings situated within these three zones (b). Indexes I, II, and III at the curves in (b) correspond to the damage distribution for three zones.

about $60 \%$ of buildings suffered only insignificant damage (damage grades 1-3). Therefore, the zonation of the city according to the vulnerability of its buildings gives the zonation of seismic risk for the different zones of the city.
Table 2. Classification-2007 of the residential blocks according to the distribution of the different types of buildings (in \%).

\begin{tabular}{llll}
\hline Types of blocks & Type A (\%) & Type B (\%) & Type C (\%) \\
\hline Type 1 & $70(77)$ & $30(23)$ & $0(0)$ \\
Type 2a & $15(7)$ & $70(86)$ & $15(7)$ \\
Type 2b & 0 & 80 & 20 \\
Type 3a & $15(6)$ & $60(36)$ & $25(58)$ \\
Type 3b & 0 & 70 & 30 \\
\hline
\end{tabular}

Note. In parenthesis, the distributions of the different types of buildings are shown according to the classification-1999 (Zobin and Ventura-Ramírez, 1999). The effect of the 2003 earthquake destroying many type-C buildings in the type-3a blocks and type-B buildings in the type-2a blocks is clear seen.

\subsection{The types of residential blocks}

The selection of a building as a unit for a seismic risk assessment is not a practical choice. As it was mentioned in (ATC13-1, 2002), it is impossible to use the damage probability derived for a class of buildings for a single-building analysis. For a single building, the uncertainty on a damage estimate can be larger than the uncertainty associated with the distribution of expected damage for a group of similar buildings. Therefore, a residential block was selected as a convenient unit for a zonation. Five types of residential blocks (Table 2; Fig. 4) were defined according to the year of construction and the distribution of the different types of buildings within them.

The five types of residential blocks in Colima were selected as characteristic for the different generations of the urban constructions. The first type is the most modern; it represents the buildings constructed after 1980 and the majority of the houses are designed with some lateral resistance to ground shaking. The second type of residential blocks was constructed between 1950 and 1980 when practically no seismo-resistant elements were applied in civil construction. The third type represented the blocks characterized by the standard cheap houses constructed during 1970-2000. Their vulnerability is close to that of the second type of block. The fourth type of block is the oldest where the traditional constructions from adobe still prevailed. The fifth type has no particular temporal association but is defined by construction from low-cost materials (not adobe) without any special project or seismo-resistant elements. The vulnerability of three of these five types was discussed by Zobin and VenturaRamírez (1999). They were identified as zones I-III.

The Type 1 (that is equivalent to zone III in Fig. 3) represents the blocks with a majority of A-type buildings and no C-type houses. Type 2a (that is equivalent to zone II in Fig. 3) represents the blocks with a majority of B-type buildings, and 
a small proportion of the A- and C-type buildings. Type $2 \mathrm{~b}$ represents the blocks of the standard low-cost houses constructed with the same project. These houses are generally equivalent to B-type houses. They were partly reconstructed by their owners to reach A-type or have been badly maintained degrading them to C-type. Type $3 \mathrm{a}$ (that is equivalent to zone I in Fig. 3) represents the blocks with a majority of B-type buildings, a small number of A-type buildings and a comparatively high number of C-type houses constructed from adobe without any special project. Type $3 \mathrm{~b}$ is characterized by a majority of B-type houses, about $30-40 \%$ of Ctype houses and the absence of A-type buildings. To estimate the mean distribution of each type of construction within residential blocks, ten characteristic blocks were selected for each of them. Calculated mean distributions are shown in Table 2.

The distributions of the different types of buildings according to the classification-1999 (Zobin and Ventura-Ramírez, 1999) are shown in Table 2 in parenthesis for comparison. The effect of the 2003 earthquake can be seen: the percentage of C-type buildings in the blocks of type 3a significantly decreased as well as the percentage of B-type buildings in the type-2a blocks (more than 1000 houses were completely destroyed or demolished within these type of blocks). This put the 3a-type blocks very close to the 2a-type blocks in terms of vulnerability.

\section{Methodology of study}

Zonation of seismic risk in Colima consists of two stages: the mapping of zones with the different types of residential blocks and the calculation of the Damage Probability Matrix (DPM) for a given level of earthquake intensity and for a given type of buildings.

\subsection{Earthquake damage scales used in this study}

Our prediction of seismic risk is probabilistic and is based on two scales of earthquake effects: we predict a damage grade for a given level of earthquake intensity. The 7-grade damage scale (Whitman, 1988) is given in Table 1. The earthquake intensity definition is based on the 12-grade Modify Mercalli (MM) scale (Wood and Neumann, 1931). The description of the damage to buildings for earthquake intensities from VII to IX is given in Table 3. There is no exact equivalence between masonry materials assumed in the MM scale (4 types) and the 3 masonry types in Colima. Therefore, we slightly modified the description of damage according to our experience in macroseismic studies of Mexican masonry after the 1995 and 2003 large Mexican earthquakes (Zobin and Ventura-Ramírez, 1998; Zobin and Pizano-Silva, 2007).
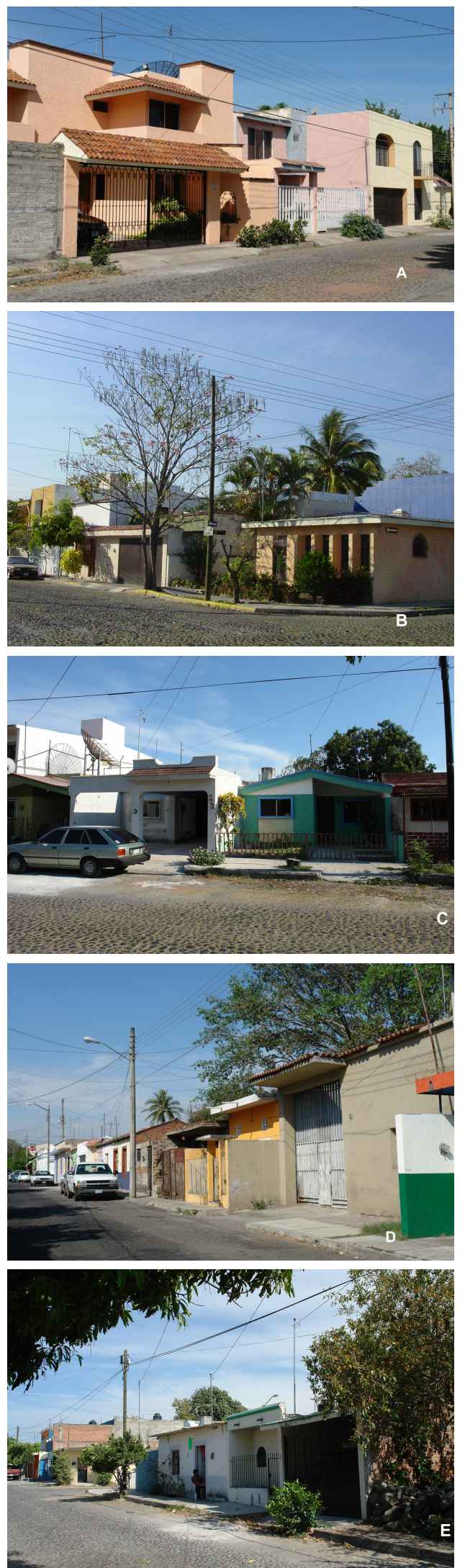

Fig. 4. Examples of five types of residential blocks: type 1 (A), type $2 \mathrm{a}(\mathbf{B})$, type $2 \mathrm{~b}(\mathbf{C})$, type $3 \mathrm{a}(\mathbf{D})$, and type $3 \mathrm{~b}(\mathbf{E})$. 
Table 3. Expected damage to buildings according to the Modify Mercalli intensity scale (extracts from Wood and Neumann, 1931, with some additions from Richter, 1958; Tiedemann, 1992).

\begin{tabular}{ll}
\hline Intensity & Description of damage \\
\hline VII & 1. Damage negligible to buildings of good design and construction (equivalent to type A). \\
& 2. Slight to moderate in well-built ordinary buildings (equivalent to type B). \\
3. Considerable in poorly built or badly designed buildings, adobe houses (equivalent to type C), including cracks. \\
VIII \\
1. Damage slight to brick structures built especially to withstand earthquakes (equivalent to type A). \\
2. Considerable in ordinary substantial buildings (equivalent to type B) with a partial collapse. \\
3. Great in poorly built structures (equivalent to type C). \\
IX \\
1. Damage considerable to masonry structures built especially to withstand earthquakes (equivalent to type A). \\
2. Great in ordinary substantial buildings (equivalent to type B), sometimes with complete collapse. \\
3. Destruction of poorly built or badly designed buildings, adobe houses (equivalent to type C).
\end{tabular}

Note. VII-1, 2 (Wood and Neumann, 1931); VII-3 (Wood and Neumann, 1931; Richter, 1958); VIII-1, 2 (Wood and Neumann, 1931); VIII-3 (Tiedemann, 1992); IX-1, 2 (Wood and Neumann, 1931); IX-3 (Richter, 1958).

Table 4. Damage probability matrix DPM-2007 (in \%) for three types of buildings in Colima (intensity MM from VII to IX).

\begin{tabular}{|c|c|c|c|c|c|c|c|c|c|}
\hline \multirow[t]{2}{*}{ DI } & \multicolumn{3}{|c|}{ Type A } & \multicolumn{3}{|c|}{ Type B } & \multicolumn{3}{|c|}{ Type C } \\
\hline & VII & VIII & IX & VII & VIII & IX & VII & VIII & IX \\
\hline 1 & 68 & 46 & 5 & 30 & 15 & 0 & 18 & 8 & 0 \\
\hline 2 & 24 & 30 & 9 & 17 & 13 & 4 & 12 & 7 & 0 \\
\hline 3 & 6 & 14 & 17 & 17 & 17 & 5 & 10 & 6 & 4 \\
\hline 4 & 2 & 5 & 31 & 25 & 15 & 10 & 10 & 11 & 4 \\
\hline 5 & 0 & 3 & 19 & 7 & 26 & 20 & 29 & 16 & 11 \\
\hline 6 & 0 & 2 & 13 & 4 & 10 & 35 & 8 & 30 & 21 \\
\hline 7 & 0 & 0 & 6 & 0 & 4 & 26 & 13 & 21 & 60 \\
\hline
\end{tabular}

Note. DI is damage index.

\subsection{Construction of the Damage Probability Matrix (DPM) for Colima buildings}

DPM represents the expert-opinion motion-damage relationships for different classes of buildings (ATC-13, 1985; ATC13-1, 2002) calculated for a set of earthquake intensities. As it was noted earlier, the first version of DPM for Colima was elaborated in 1999 (Zobin and Ventura-Ramírez, 1999). To elaborate a new DPM, which would include the experience of the 2003 earthquake, we invited the participation of 11 experts, architects, constructors, and structural scientists, with the experience in their fields from 11 to 35 years and who felt the 2003 earthquake in Colima. We prepared for them descriptions of the damage scale and earthquake intensity MM scale as shown in Tables 2 and 3. They had to give a probability of the damage grade for the types A, B, and C of buildings resulting from an earthquake with an intensity of MM VII, VIII or IX. As a result, we obtained the DPM-2007 consisting of the mean values of the predictions given by this expert group (Table 4, Fig. 5). Each column in Table 5 sums up to $100 \%$.
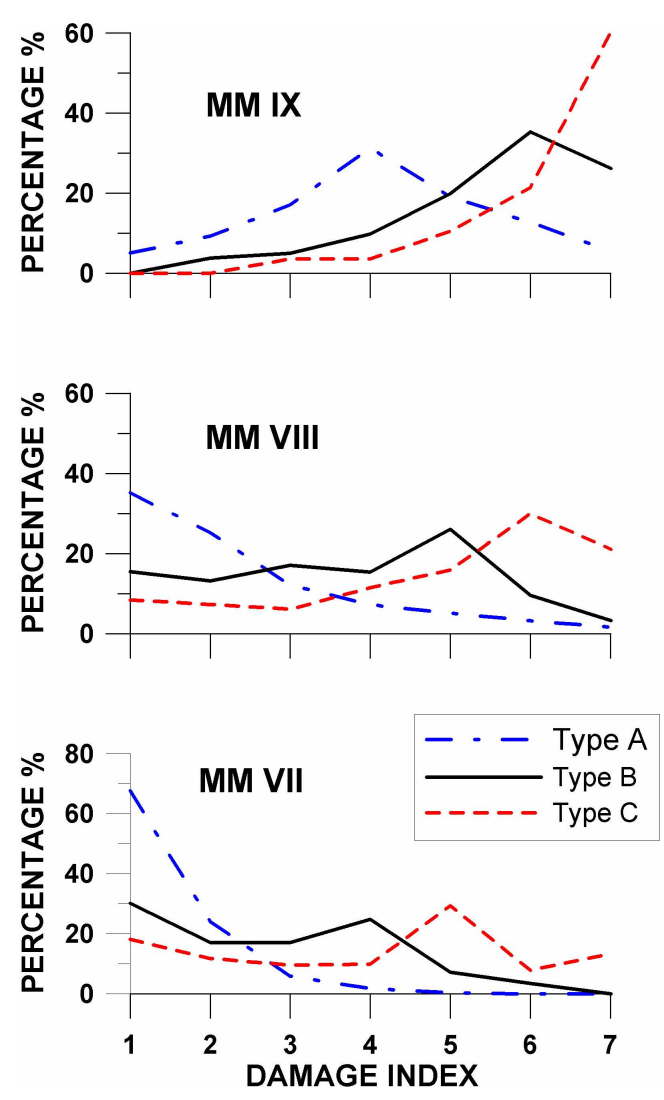

Fig. 5. Curves corresponding to the DPM-2007 for three MM intensities (VII, VIII, and IX) and three types of buildings.

The uncertainty in DPM values is based on the scatter in the opinions of the experts as to the expected average earthquake performance of a group of similar buildings and was up to $20-30 \%$. Figure 6 demonstrates this scatter in terms of standard deviations for the DPM calculated for an earthquake of intensity VIII. It is seen that for type-A buildings, 
Table 5. Damage probability matrix (in \%) for five types (1, 2a, 2b, 3a, 3b) of residential blocks in Colima (intensity MM from VII to IX).

\begin{tabular}{|c|c|c|c|c|c|c|c|c|c|c|c|c|c|c|c|}
\hline \multirow[t]{2}{*}{ DI } & \multicolumn{5}{|c|}{ VII } & \multicolumn{5}{|c|}{ VIII } & \multicolumn{5}{|c|}{ IX } \\
\hline & 1 & $2 \mathrm{a}$ & $2 b$ & $3 a$ & $3 b$ & 1 & $2 \mathrm{a}$ & $2 b$ & $3 a$ & $3 b$ & 1 & $2 a$ & $2 b$ & $3 a$ & $3 b$ \\
\hline 1 & 56 & 34 & 27 & 32 & 26 & 37 & 19 & 14 & 18 & 13 & 4 & 1 & 0 & 1 & 0 \\
\hline 2 & 23 & 18 & 16 & 17 & 16 & 25 & 15 & 12 & 14 & 11 & 8 & 4 & 3 & 4 & 3 \\
\hline 3 & 9 & 14 & 16 & 14 & 15 & 15 & 15 & 15 & 14 & 14 & 13 & 7 & 5 & 7 & 5 \\
\hline 4 & 8 & 19 & 22 & 18 & 20 & 8 & 13 & 15 & 13 & 14 & 25 & 12 & 9 & 12 & 8 \\
\hline 5 & 3 & 9 & 12 & 12 & 14 & 10 & 21 & 24 & 20 & 23 & 19 & 19 & 18 & 17 & 17 \\
\hline 6 & 1 & 4 & 4 & 4 & 5 & 4 & 12 & 13 & 14 & 16 & 19 & 30 & 32 & 28 & 31 \\
\hline 7 & 0 & 2 & 3 & 3 & 4 & 1 & 5 & 7 & 7 & 9 & 12 & 27 & 33 & 31 & 36 \\
\hline
\end{tabular}

Note. DI is damage index.

large uncertainties in the expert opinions is observed for lowdamage grades 1 and 2. For type-B buildings, most uncertainties were observed at grade 5; for type-C buildings, at grade 6. This distribution of the uncertainties shows a tendency: the most problematic prognostic is for the most likely damage grade for this type of buildings.

Based on the DPM-2007 for three types of buildings, the probability $P$ of damage for five types of residential blocks was calculated in the following way (Zobin and VenturaRamírez, 1999):

$$
\begin{aligned}
& P=k(\mathrm{~A}) p(\mathrm{~A})+k(\mathrm{~B}) p(\mathrm{~B})+k(\mathrm{C}) p(\mathrm{C}) \\
& k(\mathrm{~A})=N(\mathrm{~A}) / N(\mathrm{~A}+\mathrm{B}+\mathrm{C}) \\
& k(\mathrm{~B})=N(\mathrm{~B}) / N(\mathrm{~A}+\mathrm{B}+\mathrm{C}) \\
& k(\mathrm{C})=N(\mathrm{C}) / N(\mathrm{~A}+\mathrm{B}+\mathrm{C})
\end{aligned}
$$

Here $p(\mathrm{~A}, \mathrm{~B}$, and $\mathrm{C})$ is the probability of damage to the masonry of type A, B, and C, respectively, taken from Table 4; $N$ is the number of buildings of different type and $k(\mathrm{~A}, \mathrm{~B}$, and $\mathrm{C}$ ) is a weight coefficient for each type of masonry that formed a typical block (Table 2).

The calculated DPM for five types of residential blocks are shown in Table 5 and in Fig. 7. The damage curves show that the expected damage distributions for the residential blocks of types $2 \mathrm{a}, 2 \mathrm{~b}, 3 \mathrm{a}$, and $3 \mathrm{~b}$ for given intensities are similar. At the same time, the expected damage distribution for type 1 blocks is significantly different from other blocks demonstrating a lower level of expected damage. The empirical earthquake damage data based on the macroseismic evaluation of 3332 residential buildings in Colima that was carried out after the $2003 M_{\mathrm{w}} 7.5$ earthquake (Zobin et al., 2006) allowed a calibration of our curves showing a good coincidence of the MM VII 2003 earthquake data with the prognostic of expected damage for this intensity.
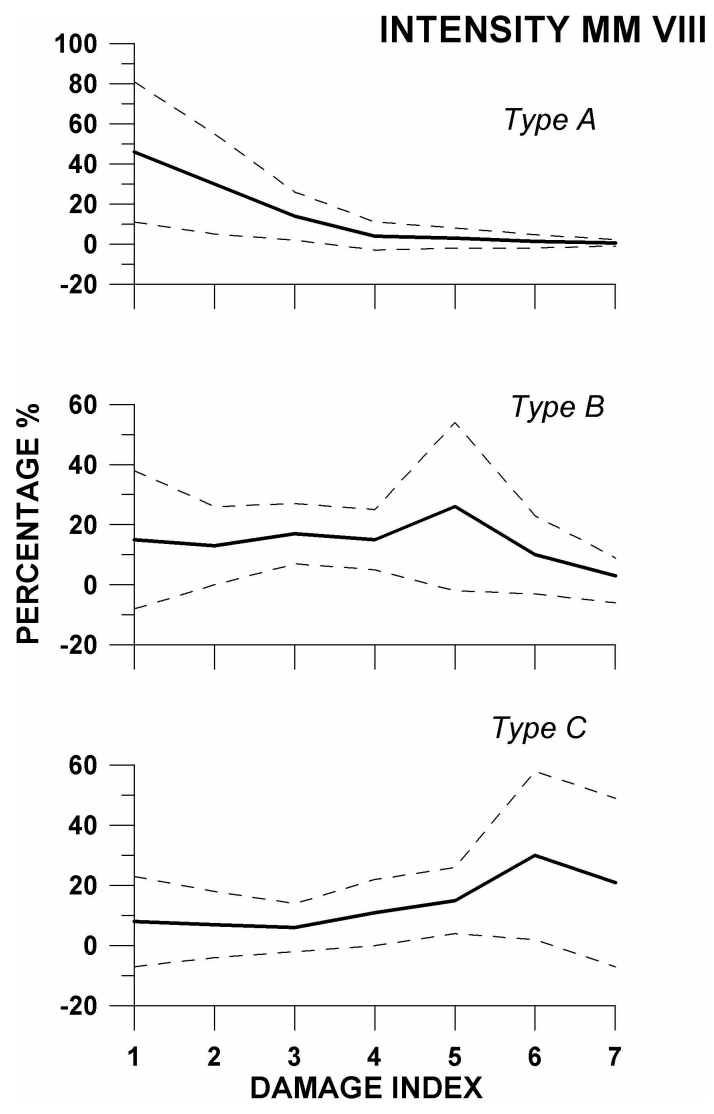

Fig. 6. Curves corresponding to the DPM-2007 (VIII MM intensity) for three types of buildings. The mean values (heavy lines) and their standard deviations (dashed lines) are shown.

\subsection{Evaluation of residential blocks}

The evaluation of the residential blocks was carried out by visual inspection. Three types of buildings may be simply identified according to a significant difference in their image (Fig. 2). Normally, a residential block consists of 10 to 

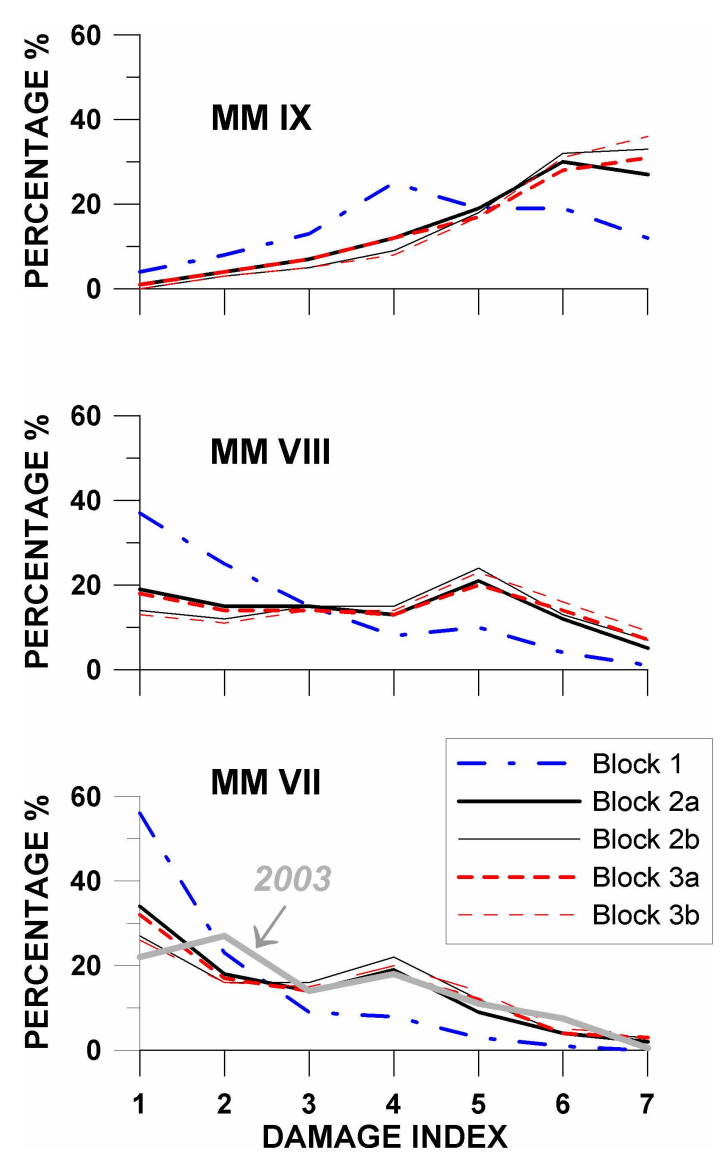

Fig. 7. Curves corresponding to the DPM-2007 for three MM intensities (VII, VIII, and IX) and five types of residential blocks.

Table 6. Distribution of the different types of residential blocks in Colima.

\begin{tabular}{lll}
\hline Type of block & Number of blocks & $\%$ of blocks \\
\hline 1 & 119 & $9 \%$ \\
$2 \mathrm{a}$ & 597 & $42 \%$ \\
$2 \mathrm{~b}$ & 244 & $17 \%$ \\
$3 \mathrm{a}$ & 187 & $13 \%$ \\
$3 \mathrm{~b}$ & 262 & $19 \%$ \\
\hline
\end{tabular}

40 buildings of different types. The presence of type- $\mathrm{C}$ and type-A buildings and their approximate percentage within the block may be estimated visually, driving along the streets. Then the classification of the blocks was made according to their definition in Table 2. An evaluation of 1466 residential blocks was carried out. The distribution of the different types of blocks is shown in Table 6 and in the histogram of Fig. 8. It can be seen that the majority (59\%) of residential blocks are of type- 2 of intermediate quality; bad quality type- 3 blocks represent $32 \%$ of all residential blocks; modern good-quality type- 1 residential blocks form only $9 \%$ of the city blocks.

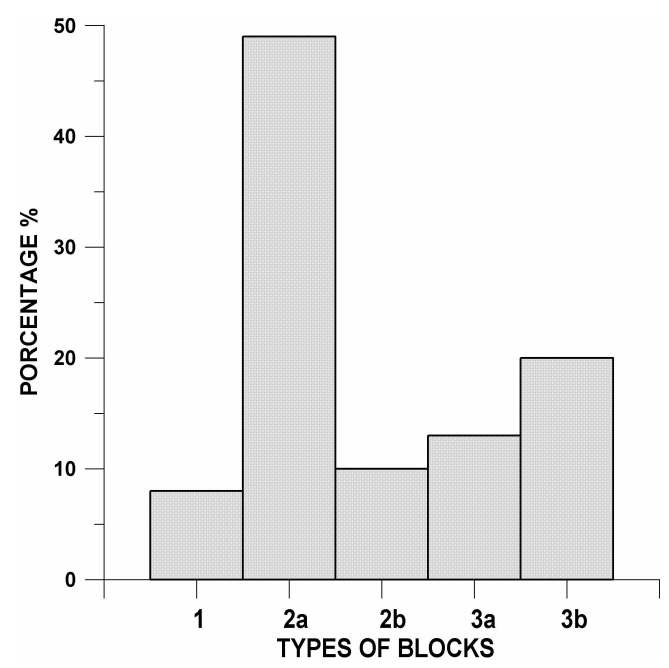

Fig. 8. Distribution of the different types of residential blocks in Colima.

\section{Seismic risk zonation}

The mapping of residential blocks and the DPM-2007 calculated for each type of residential block allowed us to propose a seismic risk microzonation for Colima.

\subsection{Mapping of residential blocks}

Figure 9 shows the position of five types of residential blocks in Colima. These residential blocks are well grouped in space allowing their regionalization. Good-quality type-1 blocks are located mainly in the northern part of the city. Type-2 blocks are distributed widely throughout the whole territory of Colima. Bad-quality type-3a blocks are situated within the historical center of Colima and its southern periphery. Bad-quality type-3b blocks are situated mainly in its eastern periphery.

\subsection{Seismic risk distribution}

As can be seen from Fig. 7, the seismic risk for types 2 and 3 residential blocks, representing $91 \%$ of all blocks, is similar. The 2003 earthquake, destroying the majority of vulnerable buildings, equalized the vulnerability of these blocks. According to Table 5, an earthquake with intensity MM VII could inflict the largest damage to residential blocks of types 2 and 3 (damage ratio $60-100 \%$ ) with a probability of $4-5 \%$ and heavy damage (damage ratio 30-60\%) with a probability of $9-14 \%$. An earthquake with intensity MM VIII could produce destruction (damage ratio 100\%) with a probability of 5-9\% and major damage with a probability of $12-16 \%$. An earthquake with intensity MM IX could destroy the majority of buildings (the total probability of major damage and destruction is $57-67 \%$ ) in these residential blocks. 


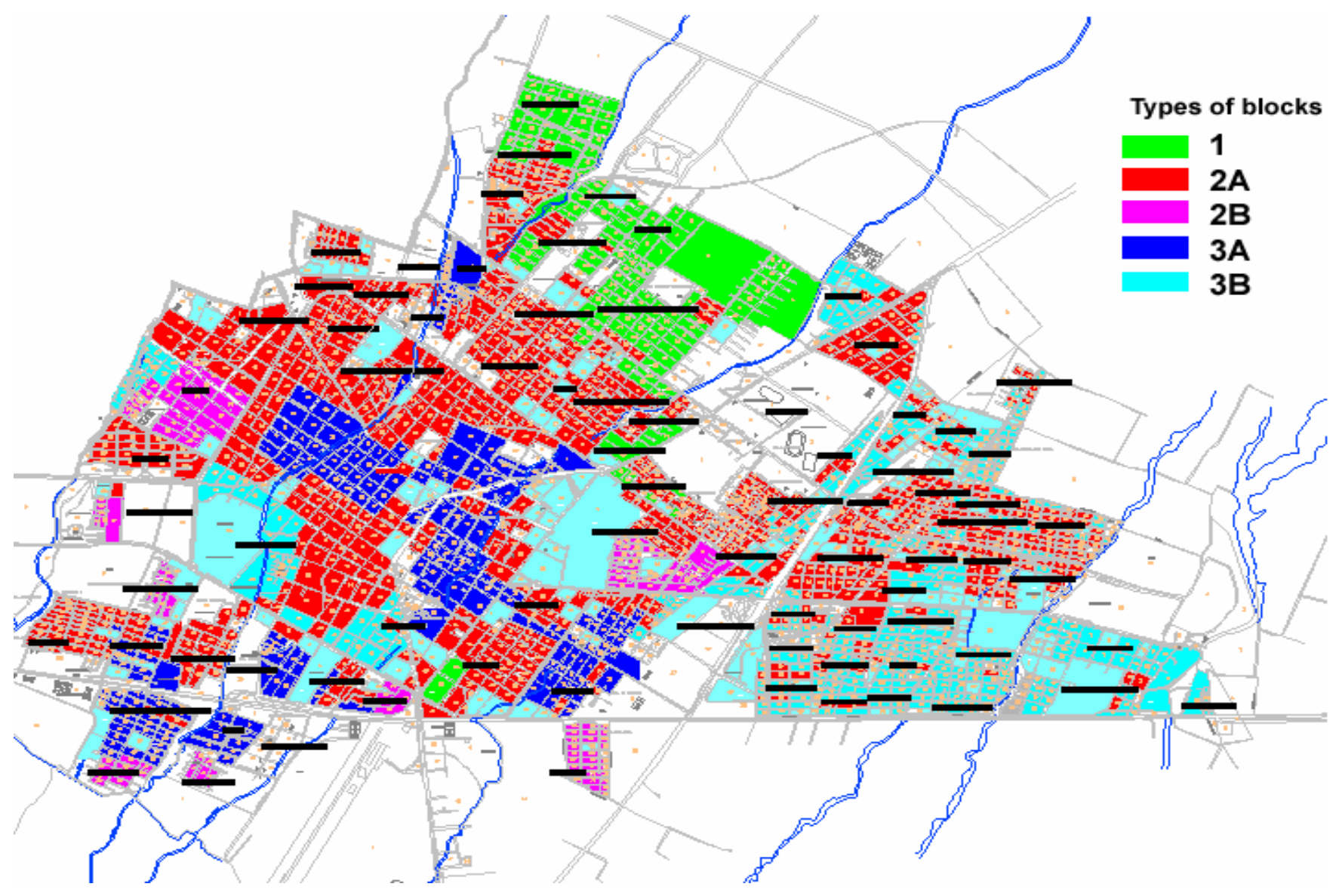

Fig. 9. Zonation of the different types of residential blocks in Colima. The residential blocks are shown by green (type 1), red (type 2a), violet (type 2 b), blue (type $3 a$ ) and cyan (type $3 b$ ) colors. The white zones show the commercial centers and federal zones.

For good-quality residential blocks of type 1, the probability of both heavy and major damage during a MM VII earthquake does not exceed 4\%. During an earthquake of intensity MM VIII, probability of destructive damage to grades 6 and 7 would not exceed 5\%. During an intensity MM IX earthquake, about a third of the buildings in zone I could be destroyed.

\subsection{Estimation of the exposure time for the microzonation of seismic risk}

The proposed DPM-2007 and the microzonation of residential blocks are valid during a specified exposure time. We estimate the "specified exposure time" as the period between two destructive earthquakes. It is expected that the next destructive earthquake will change the level of seismic risk in our area as occurred after the 2003 earthquake. We predict the level of seismic risk during this next destructive earthquake. Of course, we can expect the modification of buildings' vulnerability due to new constructions, retrofitting, material degrading, etc., but experience shows that urban development in small cities consists of expansion of the city area, rather than reconstruction of existing buildings. Only the next large earthquake may significantly change the infrastructure of the city. Therefore, we estimate this exposure time as the mean interval between the destructive earthquakes for Colima. We have the following sequence of the events: 1900, 1932, 1941, 1973, and 2003. The mean interval between them is equal to about 26 years. Therefore, we may consider our prognostic of seismic risk to be valid for the time interval up to about 2030.

\section{Results and discussion}

The seismic risk microzonation for Colima consists of two stages: mapping of residential blocks according to their vulnerability level and calculating the expert-opinion based damage probability matrix (DPM) for a given level of earthquake intensity and type of residential blocks. Together, they give a prognostic of seismic risk for the time interval between two destructive earthquakes, estimated as about 26 years. This zonation was achieved using a non-instrumental macroseismic approach based on the vulnerability of residential 

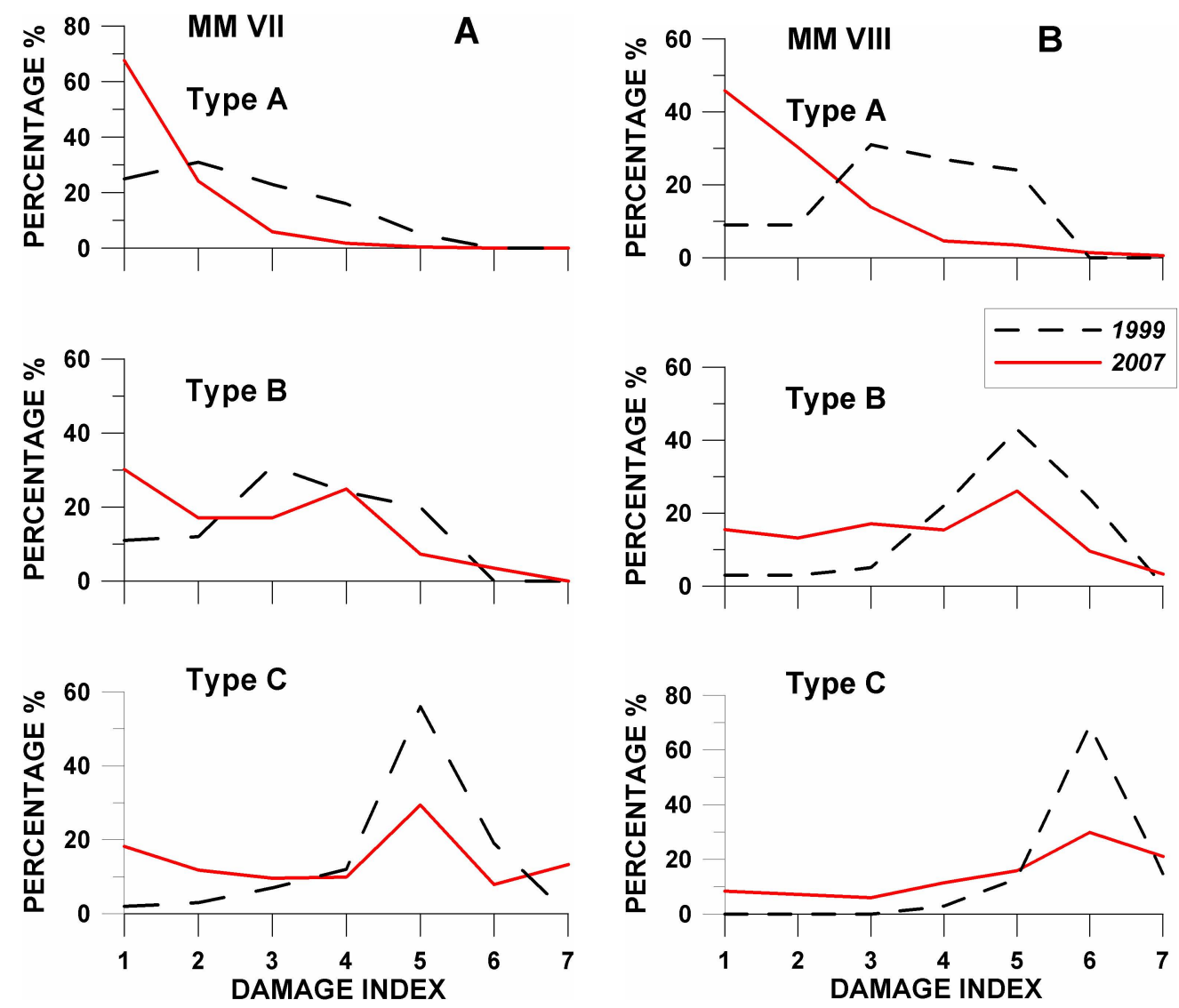

Fig. 10. Comparison between the DPM-2007 and DPM-1999 (Zobin and Ventura-Ramírez, 1999) curves. (A), for intensity MM VII; (B), for intensity MM VIII.

buildings. The method is possible because the soils of city are sufficiently homogeneous and as a consequence do not allow instrumental soil zonation.

The selection of five types of residential blocks for this study, based on differences in construction habits during different stages of urban development, was not optimal. The 2003 earthquake destroyed more than 1000 vulnerable buildings and significantly equalized the different generation blocks. Practically, we have now only two types of residential blocks: the type 1 of low vulnerability and all other blocks of higher vulnerability. Within the same type of residential block, the proposed DPM-2007 for three types of buildings may be useful for the near future.

\subsection{Comparison between DPM-2007 and DPM-1999}

A new DPM-2007 was proposed in place of the DPM-1999 calculated in 1999 (Zobin and Ventura-Ramirez, 1999). The DPM-2007 was prepared from opinions of experts who experienced the 2003 MM VII earthquake in Colima. The comparison between these two DPM (Fig. 10) shows that the 2007 experts became more optimistic regarding damage to type A buildings, significantly increasing the probability of low damage for this group. At the same time, they decreased the probability of high damage to type $\mathrm{C}$ buildings. The curves for B-type buildings are relatively similar for both DPM. The important feature of DPM-2007 is a tendency to avoid large peaks in the curves of damage. The percentage of all grades of damage is distributed more or less uniformly for the curves calculated for B- and C-type constructions. Only for A-type buildings, the low level of damage is dominant.

\subsection{Comparison between DPM-2007, DPM-ATC-13, and DPM for the buildings of Southern Italy}

ATC-13 was developed for use in estimating local, regional, and national economic impacts from earthquakes in California (ATC-13, 1985; ATC-13-1, 2002). Among other aspects, ATC-13 included the expert-opinion motion-damage relationships, presented in the form of a DPM for 40 classes of buildings. Two of these classes of buildings are similar formally to types A and B in Colima. They are: class 9, low-rise reinforced masonry shear wall buildings without momentresisting frame, similar to A-type Colima buildings; and class 75 , low-rise unreinforced masonry, similar to B-type Colima buildings. Figure 11 compares the damage curves 

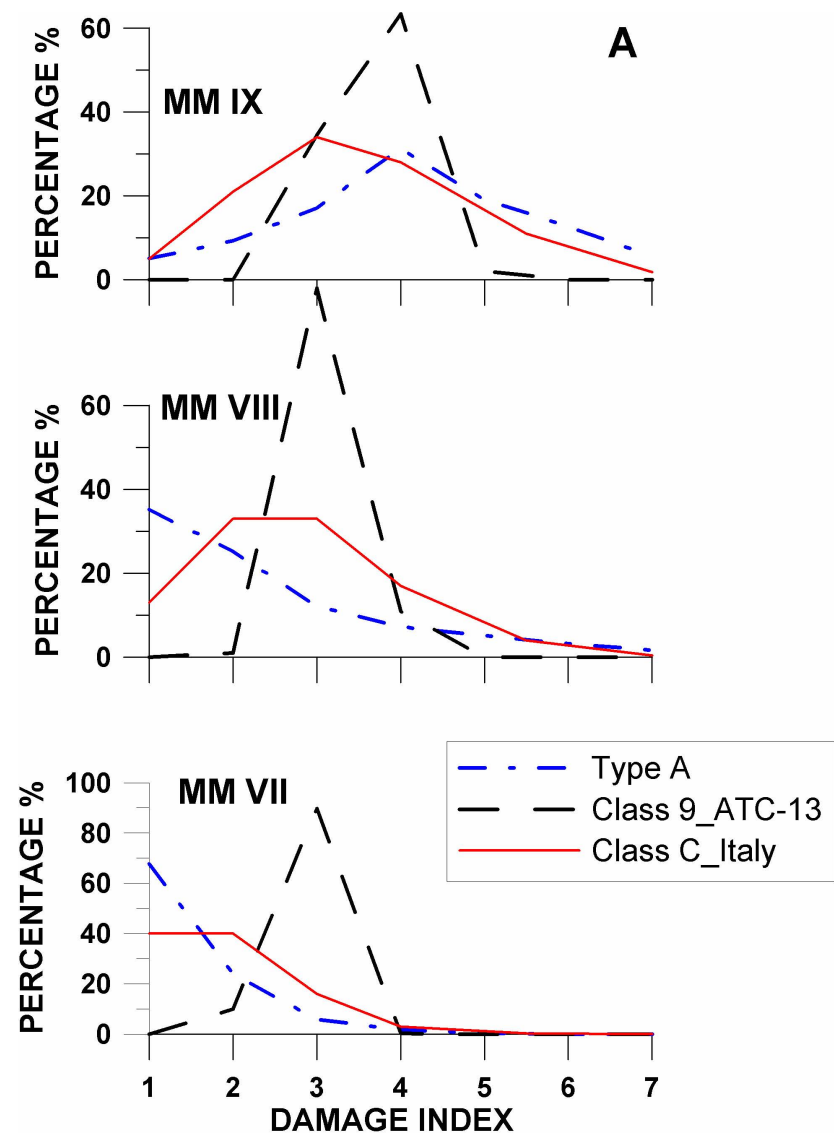
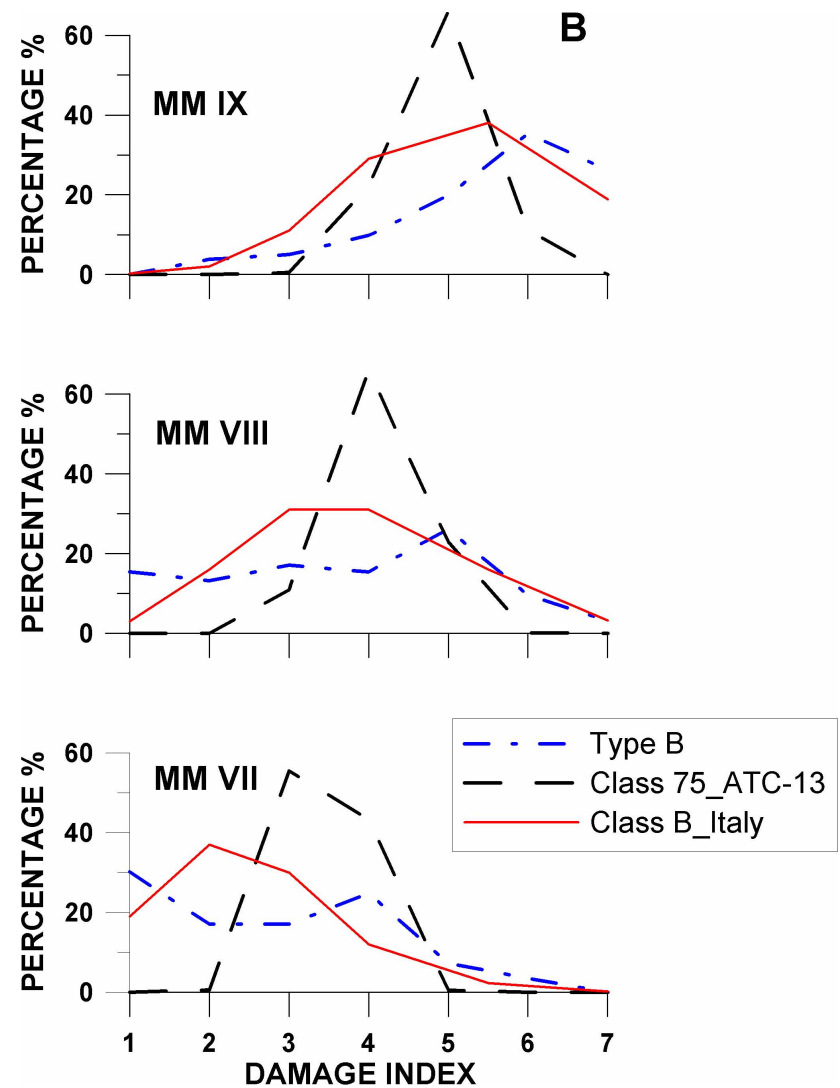

Fig. 11. Comparison between the DPM-2007, DMP_Italy (Dolce et al., 2003) and the PDM-ATC-13 (ATC-13, 1985) curves proposed for similar types of buildings. (A), for type A, class C_Italy and class 9-ATC-13; (B), for type B, class B_Italy and class 75-ATC-13.

proposed by both DPM, for California (ATC-13, 1985) and for Colima (DPM-2007). They reflect a sharp difference between expected damage to the Californian and Mexican buildings.

This difference may be conditioned, on one hand, by the different damage effects produced by the Mexican subduction earthquakes and the Californian shallow strike-slip fault earthquakes occurring along the San Andreas Fault. The Californian curves are characterized by a single sharp peak in damage distribution attributed to a dominated grade of damage while the Colima PDM curves are smoother. On the other hand, the sharp difference between expected damage to the Californian and Mexican typologies may be justified by differences between them and, above all, a different homogeneity of the buildings groups.

The comparison of DPM-2007 with the DPM constructed for the buildings of Southern Italy (Dolce et al., 2003) is shown in Fig. 11. The Italian DPM is constructed for three vulnerability classes, of high (A), medium (B) and low (C) vulnerability, mostly relevant to buildings without any seismic provision. We compare the DPM constructed for the low-vulnerability and medium vulnerability buildings with our DPM-2007 for the type A and B buildings, respectively, as we did with the Californian curves. The Italian curves have no sharp peaks and show more similarity in the behavior of damage curves with DPM-2007 than the Californian curves.

\section{Possible applications of PDM-2007}

The preliminary reconnaissance carried out in the low-rise cities of the Pacific coast areas of México (Manzanillo, Mazamitla, Pátzcuaro, Tecomán, Tepíc, Tequila, Tomatitlan, Uruapan) and Colombia (Popayan) and Perú (Arequipa, Cuzco) showed that the buildings of these cities are similar to the three types of Colima buildings. The soils beneath the cities situated within volcanic zones may be considered sufficiently homogeneous. This allows the application of this non-instrumental, inexpensive but efficient methodology for the microzonation of seismic risk in these and other cities situated in similar zones. This methodology and the calculated DPM-2007 curves may be applied also to the seismic risk microzonation for many low-rise cities in Asia and Africa. 
Acknowledgements. Juan Francisco Vargas-Mendoza, Amador Alejandres-Ayala, Oscar Rodríguez-Ramos and Rogelio Miguel Maldonado-Santa Cruz participated in the evaluation of the vulnerability of urban buildings in Colima. Authors thank the team of engineers and architects participating in the preparation of the damage probability matrix DPM-2007. Nicholas Varley helped us to improve our English grammar. The comments of Ioannis Kalogeras and an anonymous reviewer were useful. This study was partially supported by the project of CONACYT-GOBIERNO DEL ESTADO DE COLIMA No 2005-C01-2.

Edited by: M. E. Contadakis

Reviewed by: I. Kalogeras and another anonymous referee

\section{References}

ATC-13: Earthquake Damage Evaluation Data for California, Applied Technology Council, Redwood City, 492 pp., 1985.

ATC-13-1: Commentary on the use of ATC-13 earthquake damage evaluation data for probable maximum loss studies of California buildings, Applied Technology Council, Redwood City, 66 pp., 2002.

Bandy, W., Mortera-Gutierrez, C., Urrutia-Fucugaushi, J., and Hilde, T. W. C.: The subducted Rivera-Cocos plate boundary: Where is it, what is it, and what is its relationship to the Colima rift?, Geophys. Res. Lett., 22, 3075-3078, 1995.

Chávez-García, F. J., Domínguez, T., Rodríguez, M., and Pérez, F.: Site effects in a volcanic environment: a comparison between HVSR and array techniques at Colima, México, B. Seismol. Soc. Am., 97, 591-604, 2007.

Dolce, M., Masi, A., Marino, M., and Vona, M.: Earthquake damage scenarios of the building stock of Potenza (Southern Italy) including site effects, B. Earthq. Eng., 1, 115-140, 2003.

EERI: EERI Committee on seismic risk, Earthq. Spectra, 1, 33-40, 1984.

Gutiérrez, C. M., Masaka, K., Lermo, J., and Cuenca, J.: Microzonificación sísmica de la ciudad de Colima, CENAPRED, México, DF, 124 pp., 1996.
Kuroiwa, J.: Disaster Reduction, Quebecor World Peru, Lima, 496 pp., 2004.

Manual de Diseño por Sismo: Comisión Federal de Electricidad, México, DF, 162 pp., 1993.

Pacheco, J. F. and Sykes, L. R.: Seismic moment catalog of large shallow earthquakes, 1900 to 1989, B. Seismol. Soc. Am., 82, 1306-1349, 1992.

Reglamento: Reglamento de desarrollo urbano y seguridad estructural para el municipio de Colima, El suplemento del periódico oficial "El estado de Colima", 17 de febrero de 1990, 1990.

Richter, C. F.: Elementary Seismology, W.H. Freeman, San Francisco, 1958.

Tiedemann, H.: Earthquakes and Volcanic Eruptions: A Handbook on risk Assessment, Swiss Re, Zurich, 952 pp., 1992.

Whitman, R. V.: Earthquake loss estimation methodology, in: Earthquake Prognostics, edited by: Vogel, A. and Brandes, K., F. Vieweg \& Sohn, Wiesbaden, 259-278, 1988.

Wood, H. O. and Neumann, F.: Modified Mercalli Intensity Scale of 1931, B. Seismol. Soc. Am., 21, 277-283, 1931.

Zobin, V. M. and Pizano-Silva, J. A.: Macroseismic study of the $M_{\mathrm{W}} 7.521$ January 2003, Colima, México, across-trench earthquake, B. Seismol. Soc. Am., 97, 1221-1232, 2007.

Zobin, V. M. and Ventura-Ramírez, J. F.: The macroseismic field generated by the $M_{\mathrm{W}} 8.0$ Jalisco, México, earthquake of 9 October 1995, B. Seismol. Soc. Am., 88, 703-711, 1998.

Zobin, V. M. and Ventura Ramírez, J. F.: Vulnerabilidad sísmica de edificios residenciales y pronóstico de daños en caso de sismos fuertes en la ciudad de Colima, GEOS, 19, 152-158, 1999.

Zobin, V. M., Ventura-Ramírez, J. F., Gutiérrez-Andrade, C. L., Hernández-Cruz, L., and Santibáñez-Ibáñez, S.: The $M_{\mathrm{W}} 7.4$ Colima, Mexico, earthquake of 21 January 2003: The observed damage matrix in Colima city and its comparison with the probabilistic damage matrix, Nat. Hazards, 38, 391-410, 2006. 